\title{
Catalytic Stereocontrol by Scandium Trifluoromethanesulfonate in Radical Polymerization of $\alpha$-(Alkoxymethyl)acrylates
}

\author{
Shigeki HaBAUE, Hideo BARAKI, and Yoshio OKAMOTO ${ }^{\dagger}$ \\ Department of Applied Chemistry, Graduate School of Engineering, \\ Nagoya University, Furo-cho, Chikusa-ku, Nagoya 464-8603, Japan
}

(Received June 28, 2000; Accepted September 4, 2000)

\begin{abstract}
The radical polymerization of $\alpha$-(alkoxymethyl)acrylates in the presence of a catalytic amount of scandium trifluoromethanesulfonate [initiator: $\left.(i \text { - } \mathrm{PrOCO})_{2}\right)_{2}$, temp.: $30^{\circ} \mathrm{C}$ ] proceeds in an isotactic specific manner $(m \approx 70 \%)$, whereas the syndiotactic $(r \approx 70 \%)$ and atactic polymers were obtained during the radical polymerization with a catalytic amount of zinc bromide and without metal salts, respectively. The achievement of opposite sense of stereoregularity (isotactic and syndiotactic) by choosing Lewis acid catalysts during the radical polymerization of $\alpha$-(alkoxymethyl)acrylates was attained to some extent.

KEY WORDS Stereospecific Polymerization / Radical Polymerization / Scandium Trifluoromethanesulfonate / $\alpha$-(Alkoxymethyl)acrylate / Isotactic Polymer / Lewis Acid /
\end{abstract}

The stereochemical control during the radical polymerization of vinyl monomers is one of the most important topics in synthetic polymer chemistry. Although several studies on the stereospecific synthesis of vinyl polymer by radical polymerization have been reported, these methods give only an alternative stereocontrol (isotactic or syndiotactic). ${ }^{1}$ We recently reported that zinc salts $\left(\mathrm{ZnCl}_{2}\right.$ and $\left.\mathrm{ZnBr}_{2}\right)$ catalytically affect the stereochemistry during the radical polymerization of $\alpha$-(alkoxymethyl)acrylates to produce a syndiotactic polymer (up to $r$ $=71 \%$ ), ${ }^{2}$ whereas their radical polymerization without zinc halides affords an atactic polymer $(r=46 \%){ }^{2-4}$ The coordination of the zinc salts to the polar $\alpha$-substituents on the $\omega$-end of the propagating polymer and the monomer plays an important role in this system.

During the course of our research on the stereospecific radical polymerization of $\alpha$-(alkoxymethyl)acrylates, we found that the radical polymerization of benzyl $\alpha$-(methoxymethyl)acrylate (BMMA) in the presence of a catalytic amount of scandium trifluoromethanesulfonate [scandium triflate, $\left.\mathrm{Sc}(\mathrm{OTf})_{3}\right]^{5}$ proceeds in an isotactic selective manner. ${ }^{6}$ Accordingly, the achievement of the opposite sense of stereoregularity (isotactic and syndiotactic) by choosing Lewis acid catalysts during the radical polymerization of a vinyl monomer was realized to a certain extent.<smiles>C=C(COC)C(=O)OCc1ccccc1</smiles>

BMMA

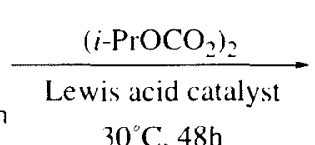

$30^{\circ} \mathrm{C} .48 \mathrm{~h}$

$\mathrm{ZnBr}_{2} \quad$ : syndiotactic $\mathrm{Sc}(\mathrm{OTf})_{3}:$ isotactic
Here, the stereospecific radical polymerization of $\alpha$ (alkoxymethyl)acrylates, BMMA, benzyl $\alpha$-(ethoxymethyl)acrylate (BEMA), and ethyl $\alpha$-(methoxyethoxymethyl)acrylate (EMEMA), using metal triflates is reported.

\footnotetext{
${ }^{\dagger}$ To whom all correspondence should be addressed.
}

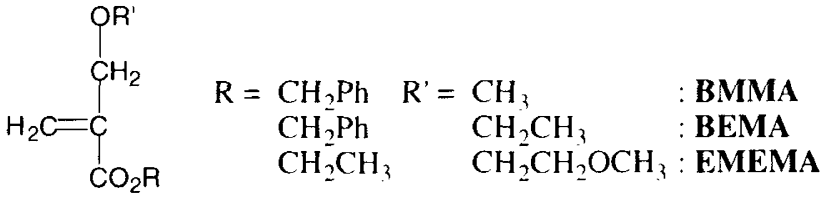

\section{EXPERIMENTAL}

\section{Materials}

The solvents and reagents were purified or prepared as previously reported. ${ }^{2,4}$ The commercially available metal triflates $\left(\mathrm{Zn}(\mathrm{OTf})_{2}, \mathrm{Sc}(\mathrm{OTf})_{3}, \mathrm{Y}(\mathrm{OTf})_{3}\right.$, etc.) were used. Monomers were synthesized from $\alpha$-(bromomethyl)acrylate ${ }^{7}$ and the corresponding alcohol using triethylamine according to the previously reported procedure. $^{4}$

Ethyl $\alpha$-(methoxyethoxymethyl)acrylate (EMEMA): ${ }^{1} \mathrm{H}$ NMR (400 MHz, $\left.\mathrm{CDCl}_{3}, \delta, \mathrm{ppm}\right): 1.30(\mathrm{t}, 3 \mathrm{H}, J=7.2$ $\left.\mathrm{Hz}, \mathrm{CH}_{3}\right), 3.40\left(\mathrm{~s}, 3 \mathrm{H}, \mathrm{OCH}_{3}\right), 3.57\left(\mathrm{~m}, 2 \mathrm{H}, \mathrm{OCH}_{2}\right), 3.66$ $\left(\mathrm{m}, 2 \mathrm{H}, \mathrm{OCH}_{2}\right), 4.22\left(\mathrm{q}, 2 \mathrm{H}, J=7.2 \mathrm{~Hz}, \mathrm{OCH}_{2}\right), 4.25$ (s, $\left.2 \mathrm{H}, \mathrm{OCH}_{2}\right), 5.90(\mathrm{~m}, 1 \mathrm{H}$, vinyl), $6.30(\mathrm{~m}, 1 \mathrm{H}$, vinyl). IR (neat, $\mathrm{cm}^{-1}$ ) 2982, 2867, 1715, 1641, 1451, 1367, 1306, 1176, 1108, 1028, 951. Anal. Calcd for $\mathrm{C}_{9} \mathrm{H}_{16} \mathrm{O}_{4}$ : C, $57.43 \%$; H, $8.57 \%$. Found: C, $57.43 \%$; H, $8.60 \%$.

\section{Polymerization (Typical Procedure)}

Polymerization was typically carried out using a metal triflates $(0.12 \mathrm{mmol})$, a monomer $(1.20 \mathrm{mmol})$, a solvent $(1.0 \mathrm{~mL})$, and diisopropyl peroxycarbonate $\left[\left(i-\mathrm{PrOCO}_{2}\right)_{2}\right]$ $(0.04 \mathrm{mmol})$ with stirring for $48 \mathrm{~h}$ at $30^{\circ} \mathrm{C}$. Reaction products for BMMA and BEMA were diluted with chloroform, precipitated into methanol, washed with methanol repeatedly, and dried in vacuo. Poly(EMEMA) was collected as a hexane insoluble part after extraction with $\mathrm{CHCl}_{3}$ from an aqueous layer.

\section{Measurements}

${ }^{1} \mathrm{H}$ NMR spectra were measured using a Varian Gemini-2000 (400 MHz for $\left.{ }^{1} \mathrm{H}\right)$ or UNITY-INOVA (500 
Table I. Radical polymerization of BMMA in the presence of a catalytic amount of $\mathrm{M}(\mathrm{OTf})_{n}{ }^{\text {a }}$

\begin{tabular}{|c|c|c|c|}
\hline \multirow{2}{*}{ Entry } & \multirow{2}{*}{ Additive(equiv.) } & Yield $^{\mathrm{b}}$ & \multirow{2}{*}{$\mathrm{DP}\left(M_{\mathrm{w}} / M_{\mathrm{n}}\right)^{\mathrm{c}}$} \\
\hline & & $\%$ & \\
\hline $1^{d}$ & - & $96^{\mathrm{c}}$ & $63(2.5)$ \\
\hline $2^{\mathrm{d}}$ & $\mathrm{ZnBr}_{2}(0.10)^{\mathrm{f}}$ & 90 & $110(3.2)$ \\
\hline 3 & $\mathrm{Zn}(\mathrm{OTf})_{2}(0.10)$ & 86 & $76(2.4)$ \\
\hline 4 & $\mathrm{Sc}\left(\mathrm{OTf}_{3}(0.12)\right.$ & 77 & $92(1.9)$ \\
\hline 5 & $\mathrm{Y}(\mathrm{OTf})_{3}(0.08)$ & 89 & $88(2.3)$ \\
\hline 6 & $\mathrm{La}(\mathrm{OTf})_{3}(0.09)$ & 88 & $91(2.1)$ \\
\hline 7 & $\mathrm{Yb}\left(\mathrm{OTf}_{3}(0.08)\right.$ & 85 & $82(2.2)$ \\
\hline 8 & $\mathrm{Sc}(\mathrm{OTf})_{3}(0.05)$ & 52 & $46(1.7)$ \\
\hline 9 & $\mathrm{Sc}(\mathrm{OTf})_{3}(0.20)$ & $31^{\mathrm{g}}$ & - \\
\hline $10^{\mathrm{h}}$ & $\mathrm{Sc}\left(\mathrm{OTf}_{3}(0.10)\right.$ & 82 & $93(1.7)$ \\
\hline $11^{\mathrm{i}}$ & $\mathrm{Sc}(\mathrm{OTf})_{3}(0.10)$ & 76 & $31(2.1)$ \\
\hline
\end{tabular}

${ }^{\mathrm{a}}[\mathrm{BMMA}] /\left[\left(i-\mathrm{PrOCO}_{2}\right)_{2}\right]=30,[\mathrm{BMMA}]=1.0 \mathrm{M}$, polymerization was carried out with stirring at $30^{\circ} \mathrm{C}$ for $48 \mathrm{~h}$ in $\mathrm{CH}_{2} \mathrm{Cl}_{2}$. ${ }^{\mathrm{b}} \mathrm{MeOH}$ insoluble part. "Determined by SEC (polystryrene standard). ${ }^{\mathrm{d}}$ Ref 2. ${ }^{\mathrm{e}}$ Hexane insoluble part. ${ }^{\mathrm{f}}$ Solvent: toluene. ${ }^{\mathrm{g}}$ The obtained polymer was partially insoluble in common organic solvents. ${ }^{\mathrm{h}}$ Polymerization time: $22 \mathrm{~h}$. 'initiator: AIBN, polymerization was conducted under UV-light irradiation without stirring at $30^{\circ} \mathrm{C}$.

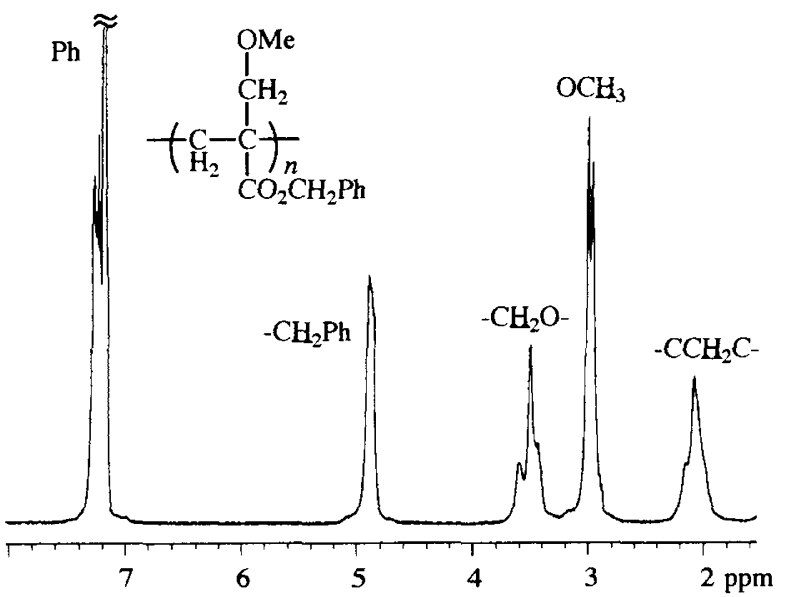

Figure 1. ${ }^{1} \mathrm{H}$ NMR spectrum of poly(BMMA) obtained with $\mathrm{Sc}(\mathrm{OTf})_{3}$ (entry 4 , Table I) $\left(\mathrm{CDCl}_{3}, 60^{\circ} \mathrm{C}\right)$.

$\mathrm{MHz}$ for ${ }^{1} \mathrm{H}$ ) spectrometer in $\mathrm{CDCl}_{3}$ or nitrobenzene- $d_{5}$ with tetramethylsilane as the internal standard. Size exclusion chromatographic analysis (SEC) was performed on a JASCO PU-986 chromatograph equipped with a JASCO RI-930 refractive index detector using two commercial columns (TSK G5000 H and Shodex AC 802.5 or TSK G3000 $\mathrm{H}$ and TSK G7000 H) connected in series with chloroform as the eluent. Calibration was performed using standard polystyrenes.

\section{RESULTS AND DISCUSSION}

The results of the radical polymerization of BMMA with various metal triflates [initiator: $\left.(i \text {-PrOCO})_{2}\right)_{2}$ ] are summarized in Table I, together with the previous data on the polymerization in the presence and absence of $\mathrm{ZnBr}_{2}$ (entries 1 and 2). ${ }^{2}$ The polymerizations in the presence of metal triflates resulted in good yields. The reaction using $\mathrm{Sc}(\mathrm{OTf})_{3}$ proceeded homogeneously in contrast to that with zinc salts, which are insoluble in

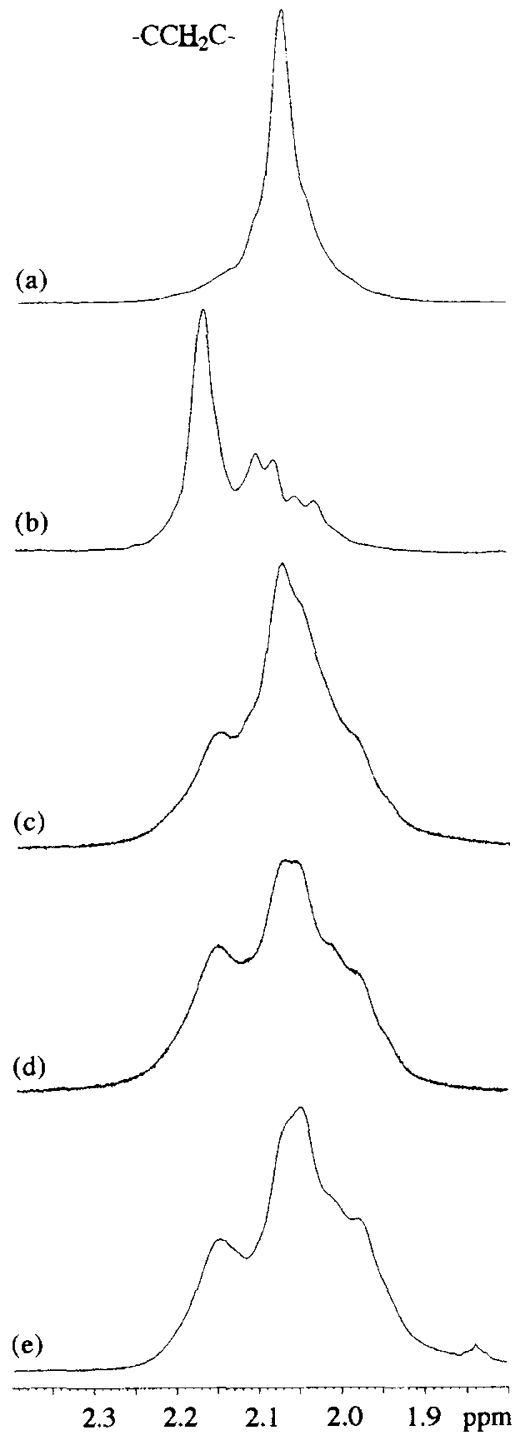

Figure 2. ${ }^{1} \mathrm{H}$ NMR spectra of the main chain methylene protons in poly(BMMA)s obtained with $n$-BuLi in toluene $(m>99 \%)(a),{ }^{4}$ by radical method with $\mathrm{ZnBr}_{2}$ (entry 2 , Table I) $(r=71 \%)(b),{ }^{2}$ with $\mathrm{Sc}$ $(\mathrm{OTf})_{3}$ (entry 4, Table I) (c), with Zn $(\mathrm{OTf})_{2}$ (entry 3 , Table I) (d), and without metal salt (entry 1 , Table I) $(e)^{2}\left(\mathrm{CDCl}_{3}, 60^{\circ} \mathrm{C}\right)$.

the reaction mixture.

Figure 1 demonstrates the ${ }^{1} \mathrm{H}$ NMR spectrum of the polymer obtained with $\mathrm{Sc}(\mathrm{OTf})_{3}$ (entry 4 , Table I). The spectral pattern for the main chain methylene protons provides information on the higher order (tetrad) tacticity, although a detailed assignment has not been made. ${ }^{2}$ Figure 2 shows the expanded ${ }^{1} \mathrm{H}$ NMR spectra of the main chain methylene protons of poly(BMMA)s obtained in the presence of $\mathrm{Sc}(\mathrm{OTf})_{3}$ (c) (entry 4, Table I) and $\mathrm{Zn}(\mathrm{OTf})_{2}$ (d) (entry 3, Table I), together with those of the polymers prepared by anionic $(\mathrm{a})^{2,4}$ and radical methods (b and e) (entries 1 and 2, Table I) ${ }^{2}$ for comparison. Although $\mathrm{ZnBr}_{2}$ effectively changed the stereoregularity of poly(BMMA) in comparison with that of the polymer prepared without metal salt, $\mathrm{Zn}(\mathrm{OTf})_{2}$ had a little effect on the stereocontrol. Similar spectral patterns were observed for the polymers obtained with other metal triflates except $\mathrm{Sc}(\mathrm{OTf})_{3}$. The pattern for the polymer prepared using $\mathrm{Sc}(\mathrm{OTf})_{3}$ is quite different from those of the polymers obtained in the presence of $\mathrm{ZnBr}_{2}$, as well as by 

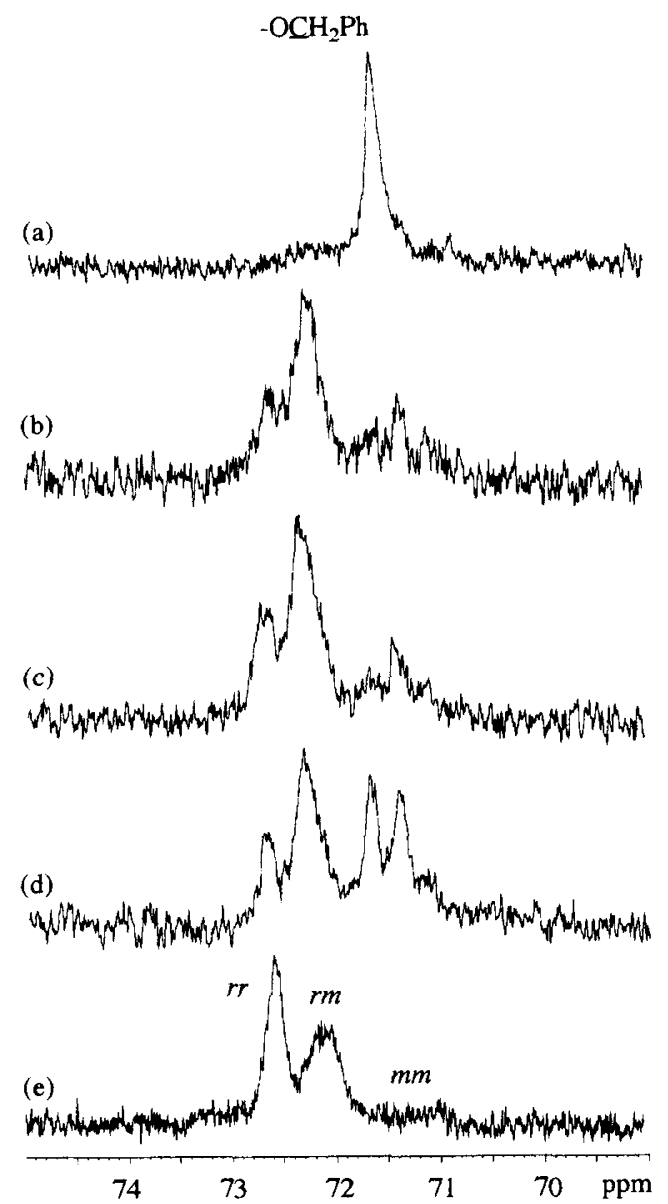

Figure 3. ${ }^{13} \mathrm{C}$ NMR spectra of the methylene carbon in the ester groups of poly(BMMA)s prepared with $n$-BuLi in toluene (a) ${ }^{4}$ obtained by normal radical method (entry 1 , Table I) (b), ${ }^{2}$ with $\mathrm{Zn}(\mathrm{OTf})_{2}$ (entry 3, Table I) (c), with $\mathrm{Sc}(\mathrm{OTf})_{3}$ (entry 4, Table I) (d), and with $\mathrm{ZnBr}_{2}$ (entry 2 , Table I) $(\mathrm{e})^{2}\left(\mathrm{CDCl}_{3}, 60^{\circ} \mathrm{C}\right)$

Table II. Anionic and radical polymerizations of BEMA and EMEMA $^{\text {a }}$

\begin{tabular}{|c|c|c|c|c|c|}
\hline \multirow{2}{*}{ Entry } & \multirow{2}{*}{ Monomer } & \multirow{2}{*}{ Initiator } & \multirow{2}{*}{ Additive } & Yield $^{b}$ & \multirow{2}{*}{$\mathrm{DP}\left(M_{\mathrm{w}} / M_{\mathrm{n}}\right)^{\mathrm{c}}$} \\
\hline & & & & $\%$ & \\
\hline $1^{d}$ & BEMA & $n-\mathrm{BuLi}$ & - & $98^{\mathrm{e}}$ & $70(12)$ \\
\hline $2^{d}$ & & $\left(i-\mathrm{PrOCO}_{2}\right)_{2}$ & - & 84 & $68(2.7)$ \\
\hline $3^{d}$ & & $\left(i-\mathrm{PrOCO}_{2}\right)_{2}$ & $\mathrm{ZnBr}_{2}{ }^{\mathrm{f}}$ & $97^{\mathrm{e}}$ & $56(2.6)$ \\
\hline 4 & & $\left(i-\mathrm{PrOCO}_{2}\right)_{2}$ & $\mathrm{Sc}(\mathrm{OTf})_{3}$ & $76^{\mathrm{e}}$ & $33(1.7)$ \\
\hline 5 & EMEMA & $n$-BuLi & - & 14 & $110(8.8)$ \\
\hline 6 & & $\left(i-\mathrm{PrOCO}_{2}\right)_{2}$ & - & 83 & $74(7.0)$ \\
\hline 7 & & $\left(i-\mathrm{PrOCO}_{2}\right)_{2}$ & $\mathrm{LiCl}$ & 35 & $86(1.7)$ \\
\hline 8 & & $\left(i-\mathrm{PrOCO}_{2}\right)_{2}$ & $\mathrm{ZnBr}_{2}$ & 75 & $86(2.6)$ \\
\hline 9 & & $\left(i-\mathrm{PrOCO}_{2}\right)_{2}$ & $\mathrm{Sc}\left(\mathrm{OTf}_{3}\right.$ & 73 & $44(1.9)$ \\
\hline
\end{tabular}

${ }^{a}$ Anionic polymerization: $[$ monomer $] /[n-\mathrm{BuLi}]=20$, [monomer] $=$ $1 \mathrm{M}$, temp. $=-78^{\circ} \mathrm{C}$, time $=48 \mathrm{~h}$; radical polymerization: [monomer $] /\left[\left(i-\mathrm{PrOCO}_{2}\right)_{2}\right]=30$, [additive $] /[$ monomer $]=0.1$, temp. $=30^{\circ} \mathrm{C}$, time $=48 \mathrm{~h}$. ${ }^{\mathrm{b}}$ Hexane insoluble part. ${ }^{\mathrm{c}}$ Determined by SEC (polystyrene standard). ${ }^{\mathrm{d}}$ Ref $2 \mathrm{~b} .{ }^{\mathrm{e}}$ Methanol insoluble part. ${ }^{\mathrm{f}}$ [Additive $] /[$ monomer $]=1$.

the normal radical method. It appears to be rich in isotacticity based on the spectral pattern of the highly isotactic poly(BMMA) that was anionically prepared.

In a previous paper, ${ }^{2 b}$ the triad tacticity of poly(BMMA) was estimated from the ${ }^{13} \mathrm{C}$ NMR spectrum of the methylene carbon in the ester group. Figure 3 depicts the ${ }^{13} \mathrm{C}$ NMR spectra of poly(BMMA) prepared with

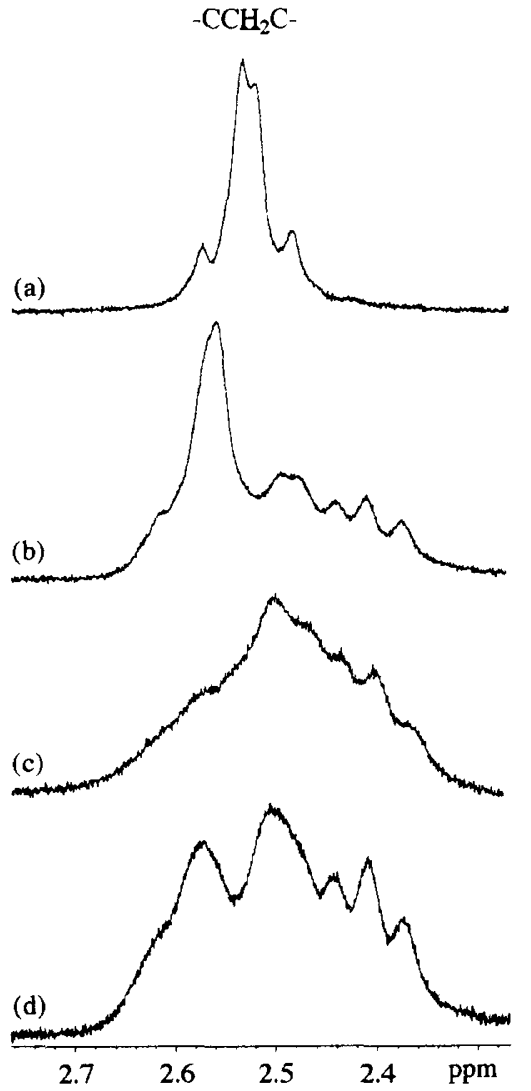

Figure 4. ${ }^{1} \mathrm{H}$ NMR spectra of the main chain methylene protons in poly(BEMA)s obtained with $n$-BuLi in toluene (entry 1 , Table II) (a), ${ }^{2}$ by radical method with $\mathrm{ZnBr}_{2}$ (entry 3 , Table II) (b), ${ }^{2}$ with Sc $(\mathrm{OTf})_{3}$ (entry 4, Table II) (c), and by normal radical method (entry 2 , Table II) $(\mathrm{d})^{2}$ (nitrobenzene- $d_{5}, 150^{\circ} \mathrm{C}$ ).

$\mathrm{Zn}(\mathrm{OTf})_{2}$ (c) (entry 3, Table I) and Sc(OTf) 3 (d) (entry 4, Table I) as additives, together with those of the polymers anionically prepared (a), radically prepared in the presence (e) (entry 2, Table I), and in the absence of $\mathrm{ZnBr}_{2}$ (b) (entry 1, Table I) for comparison. The triad tacticities ( $m m: m r: r r)$ were estimated as $25: 50: 25(m: r=50$ : $50)$ and $50: 38: 12(69: 31)$ for the polymers obtained with $\mathrm{Zn}(\mathrm{OTf})_{2}$ and $\mathrm{Sc}(\mathrm{OTf})_{3}$, while the polymer prepared with zinc bromide had a tacticity of $9: 40: 51(29: 71){ }^{2 \mathrm{~b}}$ The comparable result $[49: 38: 13(68: 32)]$ was also observed for the polymer prepared by the polymerization for $22 \mathrm{~h}$ in the presence of 0.10 equiv. of $\mathrm{Sc}(\mathrm{OTf})_{3}$ (entry 10, Table I). The isotactic polymers, evaluated as $45: 40$ : 15 (65:35) and $44: 39: 17$ (63.5:36.5), were obtained using $\mathrm{Sc}(\mathrm{OTf})_{3} \quad(0.05$ equiv., entry 8 , Table I) and $\mathrm{Sc}(\mathrm{OTf})_{3}(0.10$ equiv.) with azobisisobutyronitrile (AIBN) as an initiator under UV-light irradiation (entry 11, Table I), respectively, although the isotacticity was slightly lower than that of the polymer obtained using 0.12 equiv. of $\mathrm{Sc}(\mathrm{OTf})_{3}$. However, the polymerization using 0.20 equiv. of $\mathrm{Sc}(\mathrm{OTf})_{3}$ (entry 9 , Table I) resulted in a low yield and the obtained polymer was partially insoluble in common organic solvents, suggesting that some sidereaction like a crosslinking may take place. The radical polymerization of BMMA in the presence of $\mathrm{Sc}(\mathrm{OTf})_{3}$ proceeds in an isotactic selective manner, whereas the polymer prepared with zinc salts is rich in syndiotacticity. These results suggest that the $\mathrm{Sc}(\mathrm{OTf})_{3}$ probably co- 


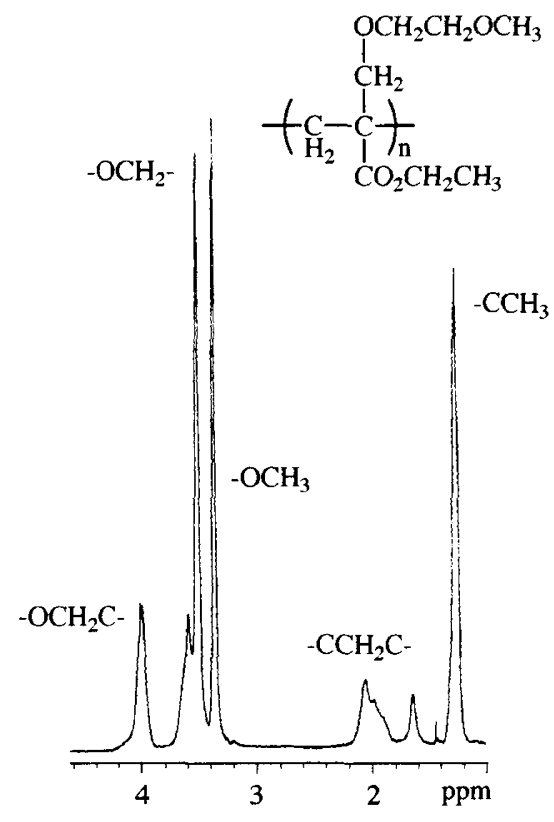

Figure 5. ${ }^{1} \mathrm{H}$ NMR spectrum of poly(EMEMA) obtained in the presence of $\mathrm{Sc}(\mathrm{OTf})_{3}$ (entry 9 , Table II) $\left(\mathrm{CDCl}_{3}, 60^{\circ} \mathrm{C}\right)$.

ordinated to the $\omega$-end of the propagating polymer and the monomer exhibits a very different effect from that of $\mathrm{ZnBr}_{2}$.

The radical polymerization of BEMA in the presence of $\mathrm{Sc}(\mathrm{OTf})_{3}(0.1$ equiv.) was also performed under the same conditions as those used for BMMA to afford poly(BEMA) in $76 \%$ yield ( $\mathrm{DP}=33, M_{\mathrm{w}} / M_{\mathrm{n}}=1.7$ ) (entry 4 , Table II). Figure 4 demonstrates the ${ }^{1} \mathrm{H}$ NMR spectra of the main chain methylene protons of the polymer obtained with $\mathrm{Sc}(\mathrm{OTf})_{3}$ (c) together with those of the polymers prepared with and without $\mathrm{ZnBr}_{2}$ (b and d) (entries 2 and 3 , Table II) and with $n-\mathrm{BuLi}$ in toluene at $-78^{\circ} \mathrm{C}$ (a) (entry 1, Table II). ${ }^{2 \mathrm{~b}}$ The spectral pattern of the polymer obtained in the presence of $\mathrm{Sc}\left(\mathrm{OTf}_{3}\right.$ is again quite different from those prepared in the presence and absence of $\mathrm{ZnBr}_{2}$, as well as that anionically prepared, indicating that some stereocontrol, probably similar to that in the polymerization of BMMA, takes place, although ${ }^{13} \mathrm{C}$ NMR analysis of poly(BEMA) was unsuccessful. $\mathrm{Sc}(\mathrm{OTf})_{3}$ seems to effectively change the stereoregularity into isotactic rich during the radical polymerization of the $\alpha$-(alkoxymethyl)acrylates.

The coordination of the zinc salts to the polar $\alpha$ substituents on the $\omega$-end of the propagating polymer and the monomer should play an important part in the stereochemical control during the radical polymerization of $\alpha$-(alkoxymethyl) acrylates. ${ }^{2}$ A novel monomer, EMEMA, which has a methoxyethoxymethyl group as an $\alpha$-substituent of acrylate, was synthesized to examine the effect on the stereocontrol in this system. The results of the anionic and radical polymerizations are listed in Table II (entries 5-9).

Figure 5 shows the ${ }^{1} \mathrm{H}$ NMR spectrum of poly(EMEMA) obtained by the radical polymerization in the presence of $\mathrm{Sc}(\mathrm{OTf})_{3}$ in $\mathrm{CH}_{2} \mathrm{Cl}_{2}$ at $30^{\circ} \mathrm{C}$ (entry 9, Table II). Each peak is assigned as shown in the figure. The ${ }^{13} \mathrm{C}$ NMR spectra of the main chain quaternary carbon in poly(EMEMA) are demonstrated in Figure 6. A sharp singlet is ob-
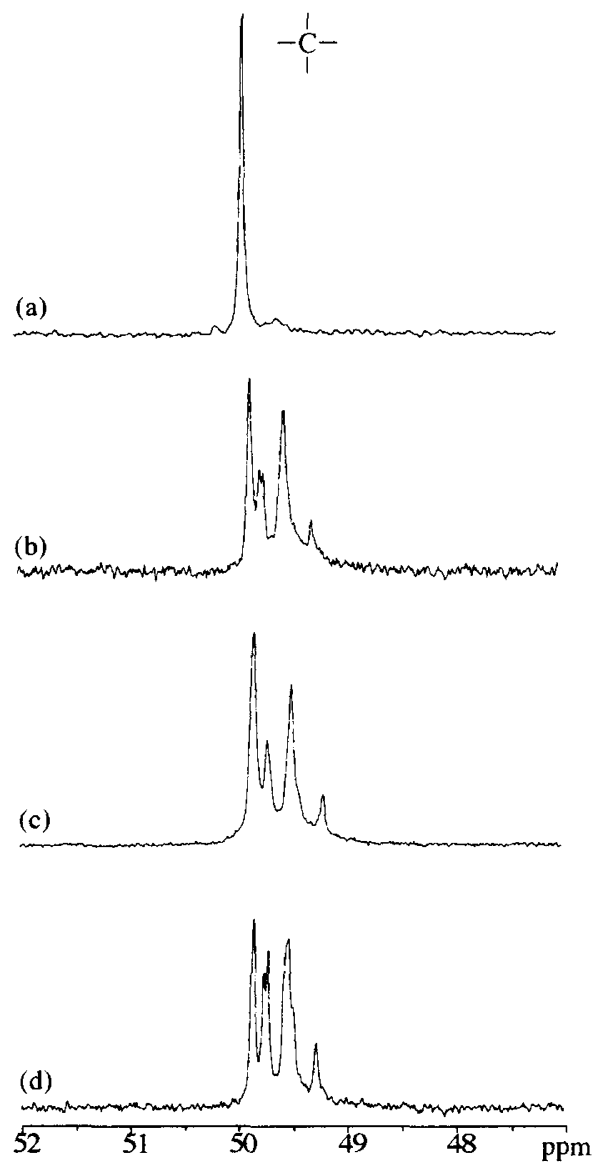

Figure 6. ${ }^{13} \mathrm{C}$ NMR spectra of the main chain quaternary carbon in poly(EMEMA)s prepared with $n$-BuLi in toluene (entry 5 , Table II) (a), obtained with $\mathrm{ZnBr}_{2}$ (entry 8, Table II) (b), with Sc(OTf) (entry 9 , Table II) (c), and by normal radical method (entry 6 , Table II) (d) $\left(\mathrm{CDCl}_{3}, 60^{\circ} \mathrm{C}\right)$.

served for the anionically obtained poly(EMEMA) (a) (entry 5, Table II), showing the polymer would have a high isotacticity based on the previous works for the anionic polymerization of $\alpha$-(alkoxymethyl)acrylates. ${ }^{4}$ The spectral patterns of the radically obtained polymers (bc) (entries 6, 8, and 9, Table II) seem to exhibit splitting due to the triad and higher order (pentad) sequences, whose detailed assignment is not clear. Although the spectral patterns of the polymers obtained using Lewis acid catalysts, $\mathrm{ZnBr}_{2}$ and $\mathrm{Sc}(\mathrm{OTf})_{3}$, are different from that of the polymer prepared by the normal radical method in the higher order sequences, the effect of Lewis acid catalysts on the stereocontrol of poly(EMEMA) appears to be much smaller than those of poly(BMMA) and poly(BEMA). The methoxyethoxymethyl group at the $\alpha$ position of acrylate may significantly change the coordination structure of the Lewis acids during the radical polymerization.

It has been reported that the anionic polymerization of $\alpha$-(alkoxymethyl)acrylates with lithium reagents proceeds in the highly isotactic-specific manner. ${ }^{4,8}$ Strong intra- and intermolecular coordination of the polar substituents of the growing polymer chain and monomers to the counter-cation $\left(\mathrm{Li}^{+}\right)$, especially, a stable six-membered chelation of intermediate lithium enolate, should be the main factor in controlling stereoregularity. Therefore, the analogous chelated transition states are plausi- 

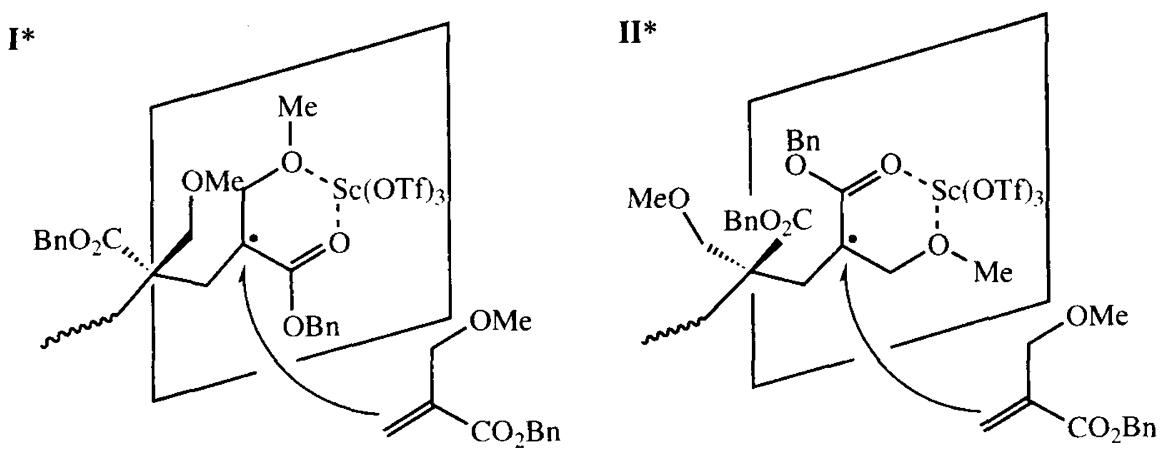

Figure 7. Isotactic-selective addition mechanism in the radical polymerization of BMMA in the presence of $\mathrm{Sc}(\mathrm{OTf})_{3}$.

ble in the isotactic-selective radical polymerization of BMMA in the presence of $\mathrm{Sc}(\mathrm{OTf})_{3}$ (Figure 7), although a detail mechanism is not immediately clear. In addition to the six-membered chelation to $\mathrm{Sc}(\mathrm{OTf})_{3}$ in the chainterminal, coordination by the polar subsituents of the penultimate unit and the monomer may be important to control the isotactic monomer addition ( $\mathrm{I}^{*}$ or $\mathrm{II}^{*}$ in Figure 7).

In conclusion, the stereospecific radical polymerization of $\alpha$-(alkoxymethyl)acrylates in the presence of a catalytic amount of $\mathrm{Sc}(\mathrm{OTf})_{3}$ was attained, and the obtained polymers were rich in isotacticity, whereas the syndiotactic and atactic polymers were obtained during the radical polymerization with a catalytic amount of zinc bromide and without metal salts, respectively. The achievement of the opposite sense of stereoregularity (isotactic and syndiotactic) by choosing Lewis acid catalysts during the radical polymerization of a vinyl monomer was attained to a certain extent.

Acknowledgments. This work was partially supported by a Grant-in-Aid for Scientific Research (No. 11450355) from the Ministry of Education, Science, Sports, and Culture of Japan, by CREST (Core Research for Evolutional Science and Technology) of Japan Science and Technology Corporation (JST), and by NEDO for the project on Technology for Novel High-Functional
Materials in Industrial Science and Technology Frontier Program, AIST.

\section{REFERENCES}

1. a) N. A. Porter, T. R. Allen, and R. A. Breyer, J. Am. Chem. Soc., 114, 7676 (1992). b) W.-X. Wu, A. T. McPhail, and N. A Porter, J. Org. Chem., 59, 1302 (1994). c) T. Nakano, M. Mori, and Y. Okamoto, Macromolecules, 26, 867 (1993). d) T. Nakano, A. Matsuda, and Y. Okamoto, Polym. J., 28, 556 (1996). e) K.Yamada, T. Nakano, and Y. Okamoto, Proc. Jpn. Acad., Ser. B, 74, 46 (1998). f) K. Yamada, T. Nakano, and Y. Okamoto, Macromolecules, 31, 7598 (1998).

2. a) S. Habaue, T. Uno, and Y. Okamoto, Polym. J., 31, 900 (1999). b) S. Habaue, T. Uno, H. Baraki, and Y. Okamoto, Macromolecules, 33, 820 (2000).

3. a) R. W. Lenz, K. Saunders, T. Balakrishnan, and K. Hatada, Macromolecules, 12, 392 (1979). b) T. Balakrishnan, R. Devarajan, and M. Santappa, J. Polym. Sci., Polym. Chem. $E d ., 22,1909$ (1984).

4. a) S. Habaue, H. Yamada, and Y. Okamoto, Macromolecules, 29, 3326 (1996). b) S. Habaue, H. Yamada, T. Uno, and Y. Okamoto, J. Polym. Sci., Part A: Polym. Chem., 35, 721 (1997). c) T. Uno, S. Habaue, and Y. Okamoto, Chirality, 10, 711 (1998). d) T. Uno, S. Habaue, and Y. Okamoto, Enantiomer, 5, 29 (2000).

5. D. Longbottom, Synlett, 2023 (1999) and the references cited therein.

6. C. L. Mero and N. A. Porter, J. Org. Chem., 65, 775 (2000).

7. J. Villieras and M. Rambaud, Synthesis, 924 (1982).

8. S. Habaue, H. Baraki, T. Shibagaki, and Y. Okamoto, Polym. J., 32, $173(2000)$. 